\title{
Amplification of 9q34 in childhood adrenocortical tumors: a specific feature unrelated to ethnic origin or living conditions
}

B.C. Figueiredo ${ }^{1}$

R.C. Ribeiro ${ }^{2,3}$, G. Zambetti4,

B. Haddad 5 ,

M.D. Pianovsky ${ }^{1}$,

R.M. Pereira ${ }^{1}$, L. DeLacerda ${ }^{1}$ and R. Sandrini ${ }^{1}$

\author{
${ }^{1}$ Unidade de Endocrinologia Pediátrica, Departamento de Pediatria, \\ Hospital de Clínicas, Universidade Federal do Paraná, Curitiba, PR, Brasil \\ Departments of ${ }^{2} \mathrm{H}$ ematology/O ncology, ${ }^{3}$ International $\mathrm{O}$ utreach Program, and \\ ${ }^{4}$ Biochemistry and Pediatrics, St. Jude Children's Research Hospital, \\ College of Medicine, University of Tennessee, Memphis, TN, USA \\ 5 Institute for Molecular and H uman Genetics and Department of Obstetrics and \\ Gynecology, Georgetown University, Washington, DC, USA
}

\section{Correspondence \\ R. Sandrini \\ Hospital de Clínicas, UFPR \\ Rua General Carneiro, 181 80060-900 Curitiba, PR \\ Brasil \\ Presented at the First International M eeting on Adrenal Disease: Basic and Clinical Aspects, Ribeirão Preto, SP, Brazil, August 31-September 2, 1999. \\ Research supported in part by $\mathrm{NCl}$ Cancer Center Core grants P30-CA-21765 and PO 1-CA-20180, and the American Lebanese Syrian Associated Charities (ALSAC).}

Received February 17, 2000 Accepted June 21, 2000

\section{Abstract}

Adrenocortical tumors (ACT) in children under 15 years of age exhibit some clinical and biological features distinct from ACT in adults. Cell proliferation, hypertrophy and cell death in adrenal cortex during the last months of gestation and the immediate postnatal period seem to be critical for the origin of ACT in children. Studies with large numbers of patients with childhood ACT have indicated a median age at diagnosis of about 4 years. In our institution, the median age was 3 years and 5 months, while the median age for first signs and symptoms was 2 years and 5 months $(\mathrm{N}=72)$. Using the comparative genomic hybridization technique, we have reported a high frequency of 9 q34 amplification in adenomas and carcinomas. This finding has been confirmed more recently by investigators in England. The lower socioeconomic status, the distinctive ethnic groups and all the regional differences in Southern Brazil in relation to patients in England indicate that these differences are not important to determine $9 q 34$ amplification. Candidate amplified genes mapped to this locus are currently being investigated and Southern blot results obtained so far have discarded amplification of the $a b l$ oncogene. Amplification of $9 \mathrm{q} 34$ has not been found to be related to tumor size, staging, or malignant histopathological features, nor does it seem to be responsible for the higher incidence of ACT observed in Southern Brazil, but could be related to an ACT from embryonic origin.
Key words

- Adrenocortical carcinoma

- Cancer

- Mutation

- 9q34 Amplification

\section{Introduction}

Childhood cancer is a very rare disease and very little is known about the etiology of most of the tumors. Distinctive age distributions of diagnostic groups of cancers have been reviewed (1-3) and some of them are related to organ-specific differences. Notably, early age peaks, such as for neuroblastoma, retinoblastoma and hepatoblastoma, are related to embryonic tumors. The pattern of age distribution of childhood adrenocorti- 
cal tumors (ACT), highest during the first 3 years of life, and the poor predictive value of prognosis based on benign or malignant histopathological patterns adapted from tumors in adults (4) are important differences between childhood and adult ACT. The patterns of clinical presentations are also quite different between them, with marked predominance of virilization associated with Cushing's syndrome in contrast to predominance of non-functional tumors in adults $(5,6)$. Moreover, the incidence of childhood ACT is markedly higher in Southern Brazil (7), while the incidence of adult ACT in this region is similar to that described in other countries, i.e., 0.5-1.0 per million (8). In the present study, we have discussed the possibility that amplified genes in 9q34 might be a cause of childhood ACT or only one feature that occurs after tumor formation. The simple fact that it is not observed in adult ACT $(9,10)$ constitutes an additional reason to believe that childhood ACT is a different entity from that usually seen in adults.

\section{Amplification of $9 q 34$}

Comparative genomic hybridization $(\mathrm{CGH})$ is a molecular cytogenetic technique based on quantitative two-color fluorescence in situ hybridization (11). Reference or control DNA isolated from an individual with a normal karyotype and tumor DNA are differentially labeled with reporter molecules (biotin d-UTP for the tumor genome and digoxigenin d-UTP for the reference genome), hybridized to reference human metaphase spreads and subsequently detected with two different fluorochromes, i.e., avidinFITC (green fluorescence; Figure 1A) for the biotinylated tumor DNA and mouse antidigoxigenin followed by rabbit anti-mouse coupled to TRITC (red fluorescence; Figure 1B) for the digoxigenin-labeled reference DNA. The differences in fluorescence intensities along the chromosomes on the reference metaphase spread reflect the copy num- ber of corresponding sequences in the tumor DNA. If chromosomes or chromosomal subregions are present in identical copy numbers in both the reference and the tumor genome, the observed fluorescence is a blend of an equal contribution of red and green fluorescence. If chromosomes are lost or chromosomal sub-regions are deleted in the tumor genome, the resulting color is shifted to red. A gain of a certain chromosome or chromosomal sub-region or an amplification at a certain chromosomal sub-region would be reflected by a more intense green staining on the respective chromosome in the reference metaphase preparation (arrows shown in Figure 1A in contrast to those shown in Figure 1B). CGH allows the detection of genetic imbalances in solid tumors or any desired test genome in a single experiment, and the determination of the chromosomal map position of gains and losses of chromosomes or chromosomal sub-regions on normal reference metaphase preparations. Evaluation of CGH was performed using a digital system (Applied Imaging, Pittsburgh, PA, USA), based on the green:red ratio.

Tumor cells are prone to intense DNA damage and imbalances across their chromosomes tend to accumulate with time, associated with advanced stage disease. A highly consistent abnormality, 9q34 amplification (Figure 1A), was found in childhood ACT by our group (12) and more recently by another group from England (10) in childhood but not in adulthood ACT, in more than $80 \%$ of tumors collected from ethnically distinct patients. This locus could be the site of genes related to the etiology or malignancy of ACT in children but not in adults (9). The most important findings described by these Swedish authors in adult ACT, increased copy number of $4 q, 5 p$ and $5 q$ and loss of chromosomes $2,11 \mathrm{q}$ and $17 \mathrm{p}$, were not found in our study. These abnormalities in adults seem to be related to the malignancy of the tumor as suggested by the scarce number of identical abnormalities found in 
adenomas.

Different CGH results between adult and childhood ACT are in agreement with the majority of studies which have proposed that the clinical and pathological findings in the adult adrenocortical tumor are largely distinct from the tumor in young patients $(5,6,13$ 15). This reinforces the concept that adult and childhood ACT are distinct entities, no matter how morphologically similar they are. We have found $9 \mathrm{q} 34$ amplification in adenomas and carcinomas, small and large tumors, which suggests a precocious onset of this abnormality. However, amplification of $9 q 34$ is not correlated with currently used histopathological parameters for defining benign and malignant features, neither could it be used as a prognostic parameter. Candidate amplified genes mapped to this locus might be the cellular oncogene c-abl $(16,17)$, the tumor suppressor gene described as tuberous sclerosis gene TSC1 $(18,19)$, which is characterized by the widespread development of distinctive tumors termed hamartomas (20). Furthermore, it has been reported that $9 \mathrm{q} 34$ encompasses the locus or the loci for ovarian cancer and the familial nevoid basal cell carcinoma syndrome (Gorlin syndrome) (21), transitional cell carcinoma of the bladder $(22,23)$ and other genes, such as steroidogenic factor 1 (24). Our Southern blot analyses have indicated that the $a b l$

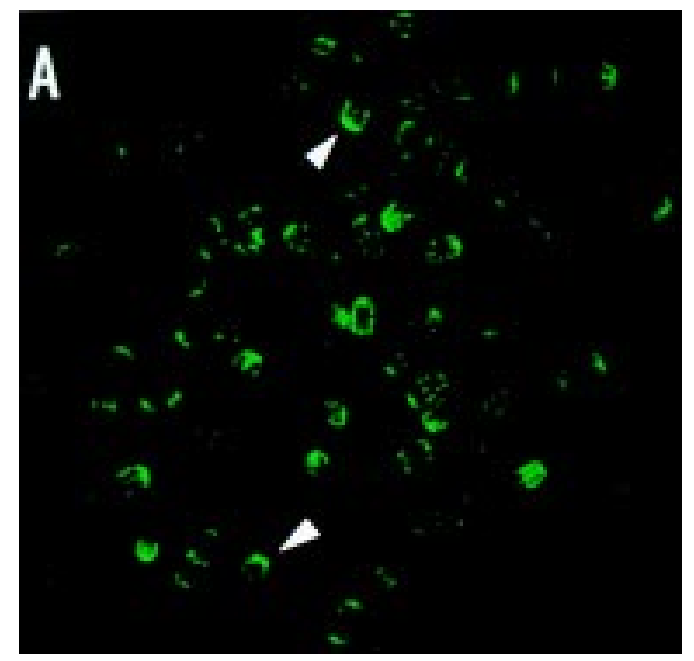

gene is not the amplified gene in childhood ACT with 9q34 amplification.

\section{Incidence of ACT and environmental pollution}

Childhood ACT in Southern Brazil and probably in the State of São Paulo appears to be 10 to 15 times greater (7) than the worldwide ACT incidence, $0.3 /$ million of children at the age of 15 years and younger (25). The second highest incidence of ACT was reported in Northwest of England between 1965 and 1986, 0.64/million of children younger than 15 years (26). It has been thought that environmental carcinogens could play a role in ACT tumorigenesis. However, reports from the families of our patients are not clearly indicative that an environmental carcinogen exists and is capable of inflicting a germline or somatic mutation. One of the hypotheses, based on reports from parents, was that ACT could be caused by a substance presently used in agriculture. Thus, we have treated dogs over three generations with the top 20 most used pesticides and herbicides in the State of Paraná (Southern Brazil), applying nontoxic concentrations of these compounds, and none of them have developed any type of tumor. These negative results are not yet sufficient to rule out the involvement of these substances, which to-

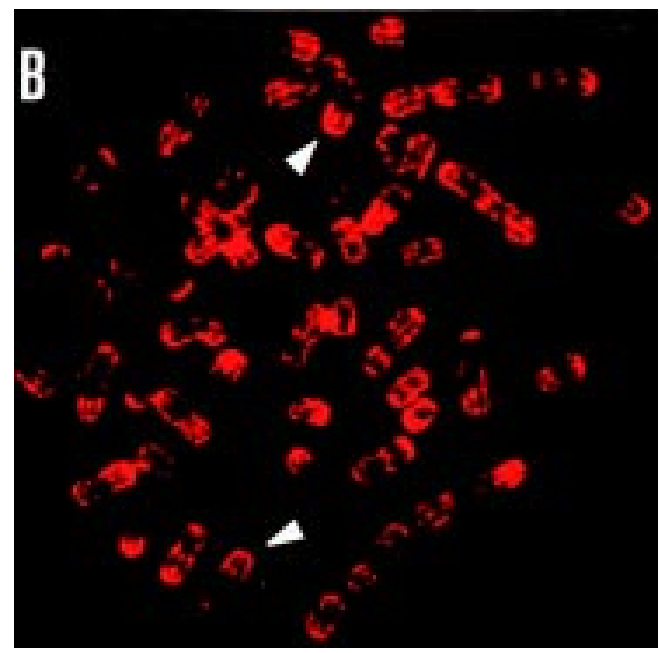

Figure 1 - Metaphase chromosome spreads from a normal male donor were hybridized with equal amounts of tumor (labeled with FITC, green fluorescence shown in Figure $1 A$ ) or control DNA (probe labeled with TRITC, the red fluorescence pattern shown in Figure 1B). Chromosome 9 indicated by arrowheads (confirmed by banding analysis seen with DAPI), showing intense signal at the far end of the long arm in $A$, is not seen in control (B). The fluorescence ratio that is different from controls is calculated by computer imaging analysis using as reference the banding pattern detected with DAPI counterstaining. 
gether with other candidate environmental pollutants must be further investigated using in vitro and in vivo approaches. However, while these hypothetical mutagens could be directly linked to other mutated genes in ACT, it seems that amplification of the $9 \mathrm{q} 34$ locus is not related to environmental or ethnic background, because their features are quite different between two regions with the exact same frequency of 9q34 in childhood ACT, Southern Brazil and Northwest of England. Although many of our patients are of European extraction (mainly Italians, Germans and Poles) there are many children, including almost half of the cases included in our CGH analysis, who are descendants of natives or of a mixture of different cultures, including Indians, blacks from Africa, Portuguese and Spaniards. In addition, the mean socioeconomic status of our patients is significantly below that found in Northwest of England and this difference does not seem to be important for generating amplification of $9 \mathrm{q} 34$.

\section{Adrenal cortex development and tumorigenesis}

A working hypothesis has been proposed, in which the origin of childhood ACT may result from an abnormality in the process of cell proliferation and/or programmed cell death during adrenal development. Studies with a significant number of ACT cases have noticed that the diagnosis is frequently made before 5 years of age $(7,27,28)$, which is in agreement with peaks of ACT diagnosis more frequently observed between 2 and 4 years of age in our experience (72 cases). The steroidogenic nature of each tumor and the ability of parents to detect any clinical manifestation usually dictate how early signs and symptoms are noticed. Most of the children's parents have noticed first signs and/or symptoms from a few months to more than a year before diagnosis. Moreover, based on sporadic observations, the elapsed time between imaging detection and referral to our institution indicates that the tumor can grow so slowly as to remain of the same size or so fast as to be several-fold larger within only a few months. Fast growth was observed in a boy who had been submitted to an upper abdomen CAT scan (for investigation of gastrointestinal tract complaints) and had incidentally documented the largest adrenal diameter to be approximately $28 \mathrm{~mm}, 5$ months before reaching $1800 \mathrm{~g}$ (during investigation of respiratory tract infection and nausea). Thus, the growth rate of ACT is quite variable and does not seem to be related to the steroidogenic state of the tumor, although non-symptomatic ACT ("non-functional ACT") tend to be diagnosed later when they become very large. Attempts to trace backward onset of signs and symptoms together with size of tumors lend support to the idea that the critical period of tumorigenesis occurs in close temporal association with the period of intense developmental transformation of the adrenal cortex. Tumors that are found less frequently in older children could indicate a slower growth rate or that the initiation of the tumor could indeed have happened later in life, a time that could offer lower risk of developing ACT through a different mechanism.

Human fetal adrenal cortex is composed of three zones: fetal zone, transitional zone and definitive zone (29). During the last 3 months of gestation, the definitive zone and transitional zone begin to take on the appearance of the glomerulosa and the zona fasciculata, respectively (30). The fetal zone corresponds to $90 \%$ of the fetal cortex and its incredible growth reaches a plateau by the end of gestation and thereafter undergoes a more intense apoptotic process and vanishes during the first 3 months of postnatal life (31). Growth in the fetal zone seems to be limited to hypertrophy of cells that migrated from the definitive zone (the migrational theory), which seems to be the only proliferative layer (32). The net effect of a period 
of intense cell proliferation, migration, hypertrophy and cell death during the early postnatal life is an adrenal without the fetal zone. The remaining two outer zones continue to expand to become adult-like in appearance, in parallel to the postnatal initiation and growth of the reticular zone that reaches its final size by adolescence. Thus, a hypothesis for an increased vulnerability of the fetal adrenal cortex is proposed based on clinical presentations of ACT most frequently found in early infancy $(7,27,28)$ and on the above mentioned peculiarities of adrenal cortex development (Figure 2).

We have postulated the hypothesis of one amplified oncogene mapped to $9 \mathrm{q} 34$ causing deregulated entry into the cell cycle and accelerated growth of ACT. Our preliminary studies with Southern blot analyses have not found amplification of the $a b l$ oncogene. However, other somatic and/or germline mutations causing dysfunction of a tumor suppressor gene, such as the TSC1 located in $9 \mathrm{q} 34$ or p53 in chromosome 17 could be directly responsible for ACT formation. In either case, a deficient TSC1
$(18,19)$ or p53 $(33)$, we would expect to find inactivation of a growth-suppressive pathway restraining activation of genes necessary for progression through $\mathrm{G} 1$, and into the $\mathrm{S}$ phase. Some of the important growth factors for adrenal cortex development such as IGF-II (34) have been related to childhood ACT (35). We do not have any scientific base to indicate that female sex hormones facilitate ACT formation; however, it has been observed that ACT occurs 5 times more frequently in girls up to the age of 5 years (7).

\section{Histological pattern of ACT}

The proposed histological features used to classify malignant and benign masses of adult ACT have been exhaustively reexamined but they cannot be reliably used to discriminate ACT subtypes in children. The ACT size does not distinguish adenoma from carcinoma; however, surgical resectability and cure, in our experience, are usually found in $92 \%$ of small tumors $\left(<200 \mathrm{~cm}^{3}\right.$, based on a 5-year survival rate), no matter if their histopathological features (those usually es-

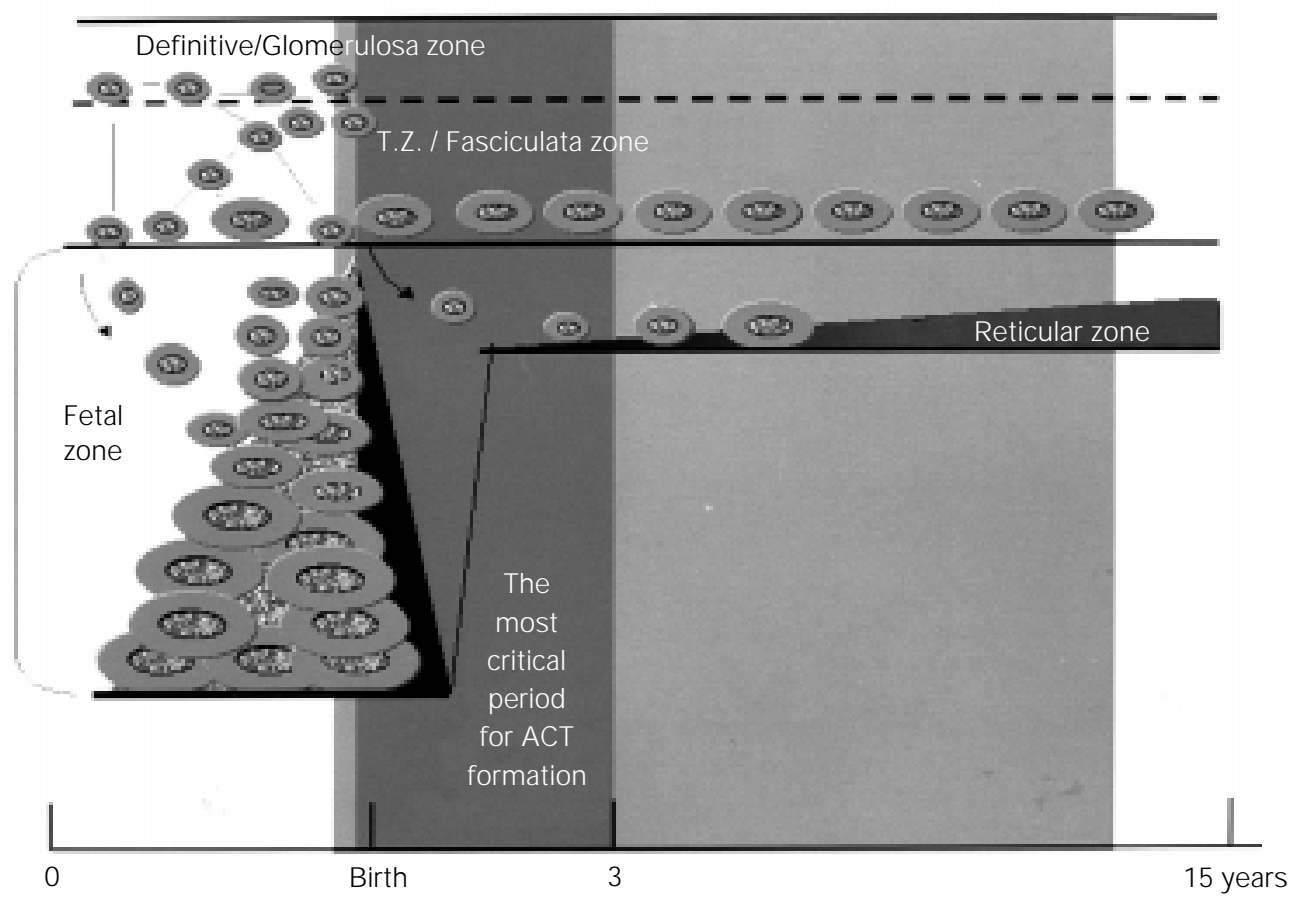

Figure 2 - The process of cell proliferation of stem cells in the definitive and transitional zones (T.Z.) in contrast to intense programmed cell death in the fetal zone (black area), and the birth of a new inner zone (reticular zone) are shown. Centripetal cell migration (arrows) to the inner zone precedes cell hypertrophy phases. The hypothetical most critical period for adrenocortical tumor (ACT) formation (dark gray rectangular area), followed by a second most frequent critical phase (light gray rectangular area) is proposed. These two critical periods are solely based on the most frequent ages at diagnosis and the time before manifesting the first signs and symptoms. 
tablished for adult ACT) are suggestive or not of malignancy. Principal prognosis criteria include tumor size, mitotic rate, stage and surgical resectability. Of these, the best two prognosis indicators appear to be tumor size (15,28,36-42) and mitotic rate according to Medeiros and Weiss (43) and Van Slooten et al. (44). It is not yet known whether carcinoma develops from adenoma or is malignant from the beginning as proposed by Weatherby and Carney (45). These authors have reported that necrosis, capsular or vascular invasion and increased mitotic activity are much more frequent in malignant tumors; however, other authors believe that the absence of these features does not exclude the possibility of a malignant biological behavior (46). Moreover, Holcombe et al. (39) have reported a significant overlap of macroscopic and microscopic features between adenomas and carcinomas. Given the importance for predicting the biological behavior of these tumors, a critical reevaluation of methods for establishing the classification of adenoma and carcinoma is required. In addition, it is necessary to investigate specific markers for embryonic tumors of the adrenal cortex in childhood ACT. Amplification of $9 \mathrm{q} 34$ was present in two small tumors with histopathological features of adenomas and absent in one advanced stage carcinoma, which is not in line with a malignization role for this imbalance. A larger number of ACT samples are necessary to verify whether $9 q 34$ could define prognosis and/or correlate with histopathological features. This amplified locus may not necessarily involve one abnormal oncogene or tumor suppressor gene. Conversely, it might be one feature found only in childhood ACT. In this regard, this finding may be a feature leading to a definition of the origin of ACT in children (embryonic tumor?) and in adults.

\section{Conclusions}

Three possibilities could be related to 9q34 amplification: one associated with ACT formation through the participation of one mutant oncoprotein or a dysfunctional tumor suppressor protein; a second possibility is that $9 \mathrm{q} 34$ occurs after tumor formation and may or may not play a role in tumor growth or in the malignization process, or this amplification does not play any role in ACT, but because of its high frequency of occurrence might be one feature of a candidate embryonic tumor. The third assumption still requires further studies to demonstrate its embryonic origin. In any of the proposed possibilities, we believe that ethnic background, living or environmental conditions, and many other differences between Southern Brazil and Northwest of England are not important factors linked to the origin of $9 \mathrm{q} 34$ amplification.

\section{References}

1. Birch J M \& Marsden HB (1987). A classification scheme for childhood cancer. International J ournal of Cancer, 40: 620624.

2. Parkin DM, Stiller CA, Bieber A, Draper GJ , Terracini B \& Young J L (Editors) (1987). International Incidence of Childhood Cancer. IARC Scientific Publications, Lyon, France.

3. Stiller CA (1992). Aetiology and epidemiology. In: Plowman PN \& Pinkerton CR (Editors), Paediatric Oncology. Chapman $\&$ Hall Medical, London, 1-22.

4. Bugg MF, Ribeiro RC, Roberson PK, Lloyd
RV, Sandrini R, Silva J B, Epelman S, Shapiro DN \& Parham DM (1994). Correlation of pathologic features with clinical outcome in pediatric adrenocortical neoplasia. A study of a Brazilian population. Brazilian Group for Treatment of Childhood Adrenocortical Tumors [see Comments]. American J ournal of Clinical Pathology, 101: 625-629.

5. Huvos AG, Hajdu SI, Brasfield RD \& Foote J r FW (1970). Adrenal cortical carcinoma. Clinicopathologic study of 34 cases. Cancer, 25: 354-361.

6. King DR \& Lack EE (1979). Adrenal corti- cal carcinoma: a clinical and pathologic study of 49 cases. Cancer, 44: 239-244.

7. Sandrini R, Ribeiro RC \& DeLacerda $L$ (1997). Childhood adrenocortical tumors. J ournal of Clinical Endocrinology and Metabolism, 82: 2027-2031.

8. Mantero F \& Arnaldi G (1999). Investigation protocol: adrenal enlargement. Clinical Endocrinology, 50: 141-146.

9. Kjellman $M$, Kallioniemi OP, Karhu $R$, Höög A, Farnebo LO, Auer G, Larsson C \& Bäckdahl M (1996). Genetic aberrations in adrenocortical tumors detected using comparative genomic hybridization corre- 
late with tumor size and malignancy. Cancer Research, 56: 4219-4223.

10. J ames LA, Kelsey AM, Birch J M \& Varley J M (1999). Highly consistent genetic alterations in childhood adrenocortical tumours detected by comparative genomic hybridization. British J ournal of Cancer, 81: 300-304.

11. du Manoir S, Speicher MR, J oos S, Schrock E, Popp S, Dohner H, Kovacs G, Robert-Nicoud M, Lichter P \& Cremer T (1993). Detection of complete and partial chromosome gains and losses by comparative genomic hybridization. Human Genetics, 90: 590-610.

12. Figueiredo $B C$, Stratakis $C A$, Sandrini $R$, DeLacerda L, Pianovsky MA, Giatzakis C, Young HM \& Haddad BR (1999). Comparative genomic hybridization analysis of adrenocortical tumors of childhood. J ournal of Clinical Endocrinology and Metabolism, 84: 1116-1121.

13. Bertagna $C \&$ Orth DN (1981). Clinical and laboratory findings and results of therapy in 58 patients with adrenocortical tumors admitted to a single medical center (1951 to 1978). American J ournal of Medicine, 71: 855-875.

14. Bodie B, Novick AC, Pontes J E, Straffon RA, Montie JE, Babiak T, Sheeler L \& Schumacher $P$ (1989). The Cleveland Clinic experience with adrenal cortical carcinoma. J ournal of Urology, 141: 257-260.

15. Hayles AB, Hahn J rHB, Sprague RG, Bahn RC \& Priestley JT (1966). Hormone-secreting tumors of the adrenal cortex in children. Pediatrics, 37: 19-25.

16. Mohamed AN, Koppitch F, Varterasian M, Karanes C, Yao KL \& Sarkar FH (1995). $B C R / A B L$ fusion located on chromosome 9 in chronic myeloid leukemia with a masked Ph chromosome. Genes, Chromosomes and Cancer, 13: 133-137.

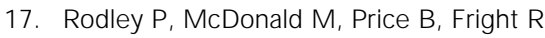
\& Morris C (1997). Comparative genomic hybridization reveals previously undescribed amplifications and deletions in the chronic myeloid leukemia-derived K-562 cell line. Genes, Chromosomes and Cancer, 19: 36-42.

18. Green AJ , J ohnson PH \& Yates J R (1994). The tuberous sclerosis gene on chromosome $9 q 34$ acts as a growth suppressor. Human Molecular Genetics, 3: 18331834.

19. Bjornsson J, Short MP, Kwiatkowski DJ \& Henske EP (1996). Tuberous sclerosis-associated renal cell carcinoma. Clinical, pathological, and genetic features. American J ournal of Pathology, 149: 1201-1208.

20. Van Slegtenhorst M, de Hoogt R, Her- mans C, Nellist $M$, J anssen B, Verhoef $S$, Lindhout $D$, van den Ouweland $A$, Halley $D$, Young J , Burley M, J eremiah S, Woodward K, Nahmias J, Fox M, Ekong R, Osbome J, Wolfe J, Povey S, Snell RG, Cheadle J P, J ones AC, Tachataki M, Ravine D \& Kwiatkowski DJ (1997). Identification of the tuberous sclerosis gene TSC1 on chromosome 9q34. Science, 277: 805-808.

21. Devlin J, Elder PA, Gabra H, Steel CM \& Knowles MA (1996). High frequency of chromosome 9 deletion in ovarian cancer: evidence for three tumour-suppressor loci. British J ournal of Cancer, 73: 420423.

22. Habuchi T, Devlin J , Elder PA \& Knowles MA (1995). Detailed deletion mapping of chromosome $9 q$ in bladder cancer: evidence for two tumour suppressor loci. Oncogene, 11: 1671-1674.

23. Hornigold $N$, Devlin J, Davies AM, Aveyard J S, Habuchi T \& Knowles MA (1999). Mutation of the 9q34 gene TSC1 in sporadic bladder cancer. Oncogene, 18: 2657-2661.

24. Taketo $M$, Parker $K L$, Howard TA, Tsukiyama T, Wong M, Niwa O, Morton CC, Miron PM \& Seldin MF (1995). Homologs of Drosophila Fushi-Tarazu factor 1 map to mouse chromosome 2 and human chromosome 9q33. Genomics, 25: 565-567.

25. Gurney J G, Severson RK, Davis S \& Robison LL (1995). Incidence of cancer in children in the United States. Sex-, race-, and 1-year age-specific rates by histologic type. Cancer, 75: 2186-2195.

26. Birch J M \& Blair V (1988). Increase in childhood carcinomas in north-west England [Letter]. Lancet, 1: 833.

27. Hartley AL, Birch J M, Marsden HB, Reid H, Harris M \& Blair V (1987). Adrenal cortical tumours: epidemiological and familial aspects. Archives of Disease in Childhood, 62: 683-689.

28. Lefevre M, Gerard-M archant R, Gubler J $P$, Chaussain J L \& Lemerle J (1984). Adrenal cortical carcinoma in children: 42 patients treated from 1958 to 1980 at Villejuif. In: Humphrey GB, Grindley GB \& Dehner LP (Editors), Adrenal and Endocrine Tumors in Children. Adrenal Cortical Carcinoma and Multiple Endocrine Neoplasia. Martinus Nijhoff Publishers, Boston, 265-276.

29. Mesiano S \& J affe RB (1997). Developmental and functional biology of the primate fetal adrenal cortex. Endocrine Reviews, 18: 378-403.

30. Sucheston ME \& Cannon MS (1968). Development of zonular patterns in the hu- man adrenal gland. J ournal of Morphology, 126: 477-491.

31. Spencer SJ , Mesiano S, Lee J Y \& J affe RB (1999). Proliferation and apoptosis in the human adrenal cortex during the fetal and perinatal periods: implications for growth and remodeling. J ournal of Clinical Endocrinology and Metabolism, 84: 1110-1115.

32. Keene MFL \& Hewer EE (1927). Observations on the development of the human suprarenal gland. J ournal of Anatomy, 61: 302-324.

33. Varley J M, Thorncroft M, McGown G, Appleby J, Kelsey AM, Tricker KJ , Evans DG \& Birch J M (1997). A detailed study of loss of heterozygosity on chromosome 17 in tumours from Li-Fraumeni patients carrying a mutation to the TP53 gene. Oncogene, 14: 865-871.

34. Mesiano S \& J affe RB (1997). Role of growth factors in the developmental regulation of the human fetal adrenal cortex. Steroids, 62: 62-72.

35. Ilvesmäki V, Kahri Al, Miettinen PJ \& Voutilainen R (1993). Insulin-like growth factors (IGFs) and their receptors in adrenal tumors: high IGF-II expression in functional adrenocortical carcinomas. J ournal of Clinical Endocrinology and Metabolism, 77: 852-858.

36. Benaily $M$, Schweisguth $O \&$ J ob JC (1975). Les tumeurs cortico-surrenales de l'enfant. Etude retrospective de 34 cas observes de 1954 a 1973. Archives Françaises de Pediatrie, 32: 441-453.

37. Cagle PT, Hough AJ , Pysher TJ , Page DL, J ohnson EH, Kirkland RT, Holcombe J H \& Hawkins EP (1986). Comparison of adrenal cortical tumors in children and adults. Cancer, 57: 2235-2237.

38. Chudler RM \& Kay R (1989). Adrenocortical carcinoma in children. Urologic Clinics of North America, 16: 469-479.

39. Holcombe J H, Pysher TJ \& Kirkland RT (1984). Functioning adrenocortical tumors in childhood. In: Humphrey GB, Grindey GB \& Dehner LP (Editors), Adrenal and Endocrine Tumors in Children. Adrenal Cortical Carcinoma and Multiple Endocrine Neoplasia. Martinus Nijhoff Publishers, Boston, 277-290.

40. Neblett WW, Frexes-Steed M \& Scott J $r$ HW (1987). Experience with adrenocortical neoplasms in childhood. American Surgery, 53: 117-125.

41. Ribeiro RC, Sandrini Neto RS, Schell MJ , Lacerda L, Sambaio GA \& Cat I (1990). Adrenocortical carcinoma in children: a study of 40 cases. J ournal of Clinical Oncology, 8: 67-74. 
42. Tang CK \& Gray GF (1975). Adrenocortical neoplasms. Prognosis and morphology. Urology, 5: 691-695.

43. Medeiros LJ \& Weiss LM (1992). New developments in the pathologic diagnosis of adrenal cortical neoplasms. J ournal of Clinical Pathology, 97: 73-83.

44. Van Slooten H, Schaberg A, Smeenk D \&
Moolenaar AJ (1985). Morphologic characteristics of benign and malignant adrenocortical tumors. Cancer, 55: 766773.

45. Weatherby RP \& CarneyJ A (1984). Pathologic features of childhood adrenocortical tumors. In: Humphrey GB, Grindey GB \& Dehner LP (Editors), Adrenal and Endo- crine Tumors in Children. Adrenal Cortical Carcinoma and Multiple Endocrine Neoplasia. Martinus Nijhoff Publishers, Boston, 239-248.

46. Stewart DR, J ones PH \& J olleys A (1974). Carcinoma of the adrenal gland in children. J ournal of Pediatric Surgery, 9: 5967. 